\title{
Cyclosporin A: tissue levels following topical and systemic administration to rabbits
}

\author{
T A G BELL' AND A G HUNNISETT ${ }^{2}$ \\ From the 'Oxford Eye Hospital and the ${ }^{2}$ Renal Unit, Churchill Hospital, Oxford
}

SUmmary Plasma and aqueous levels of cyclosporin A (CsA) were determined following topical administration of CsA $1 \%$ to healthy rabbit eyes and compared with levels obtained when administered to rabbit eyes which had received corneal grafts 7-10 days previously. In addition plasma levels were determined following intramuscular administration of $50 \mathrm{mg}$ CsA and the results compared with those obtained following topical administration. Topical administration to healthy rabbit eyes five times a day for three days resulted in plasma levels of CsA which were similar to those obtained over three days following an intramuscular administration of $50 \mathrm{mg}$ CsA. The plasma levels in both were significantly higher than those obtained following topical administration to rabbit eyes which had received corneal grafts 7-10 days previously. Aqueous levels of CsA were lower than plasma levels, and there was no significant difference between levels obtained when CsA was administered topically to healthy eyes, to eyes which had received corneal grafts, or to the fellow eye.

Cyclosporin A (CsA) has been shown in a number of animal investigations to be effective in prolonging the survival or corneal grafts when administered intramuscularly, topically to the eye which had received the graft, or when given as a retrobulbar injection. ${ }^{1-7}$

It has been suggested that when administered topically the drug may act locally. ${ }^{3.7}$ In support of this it has been reported that the survival time of corneal grafts in five rabbits was not prolonged when the CsA was administered topically to the other eye. ${ }^{7}$ It is surprising that this result was obtained, because therapeutic levels of CsA were detected in the plasma.

We decided to investigate further the plasma and aqueous levels of CsA following topical administration to rabbit eyes and to compare them with those obtained when CsA was administered intramuscularly. We considered it was important to determine the tissue levels obtained after topical administration to eyes which had recently received corneal grafts, as CsA is known to be particularly effective when administered during the first few days following an allogeneic graft. ${ }^{\text {" }}$

Correspondence to T A G Bell, FRCSEd, Oxford Eyc Hospital, Walton Strect. Oxford OX2 6AN.

\section{Materials and methods}

CYCLOSPORIN A

Cyclosporin A (Sandoz) was dissolved in arachis oil in a concentration $1 \mathrm{~g} / 100 \mathrm{ml}(=10 \mathrm{~g} / \mathrm{l})$. The solution was heat sterilised and prepared in $10 \mathrm{ml}$ bottles.

ANAESTHESIA

The animals were anaesthetised with intramuscular 'Hypnorm' (fentanyl citrate and fluanisone) $1 \mathrm{ml} / \mathrm{kg}$. Adequate neuroleptanaesthesia was obtained to enable cornea grafts to be performed and to allow removal of samples of aqueous and blood.

\section{CORNEAL GRAFTING}

New Zealand white rabbits were killed, and $6.0 \mathrm{~mm}$ donor penetrating corneal grafts were trephined. Dutch rabbits of weight $2 \mathrm{~kg}$ were used as recipients. Guttae cyclopentolate $1 \%$ and guttae phenylephrine $10 \%$ were instilled into the eye. 10000 units of heparin was administered intravenously to prevent aqueous clotting. The superior and inferior recti muscles were secured with $6 / 0$ silk sutures. A $5.5 \mathrm{~mm}$ central corneal button was trephined. The $6.0 \mathrm{~mm}$ donor button was sutured with eight interrupted $10 / 0$ nylon sutures. Further sutures were added if 


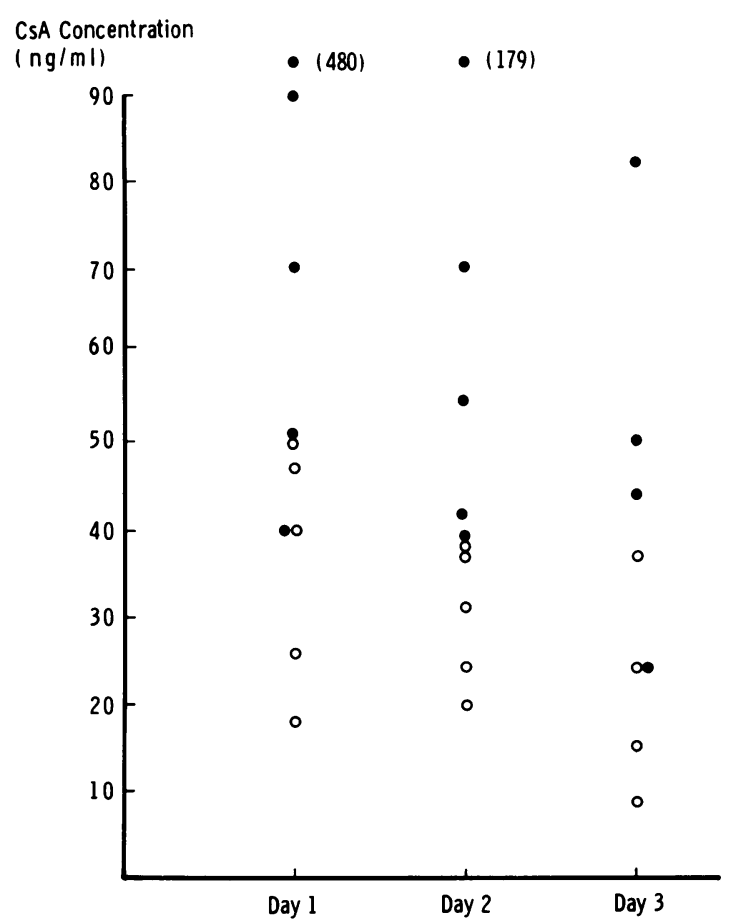

Fig. 1 Plasma and aqueous levels of CsA obtained following topical CsA five times a day to healthy eyes. Samples were obtained daily. The solid spots indicate plasma levels and the open circles aqueous levels. (SI conversion: $n g / m l=\mu \mathrm{g} / \mathrm{l}$.)

required, and the anterior chamber was reformed with air. Guttae chloramphenicol $0.5 \%$ was instilled and 1 mega unit of penicillin was injected intramuscularly. The lids were closed with a tarsorrhaphy stitch.

\section{SAMPLING OF AQUEOUS AND PLASMA}

Each rabbit was anaesthetised and a 25 gauge needle was inserted into the anterior chamber. $0.25 \mathrm{ml}$ of aqueous was removed. Any sample contaminated with blood was discarded. $1 \mathrm{ml}$ of blood was removed from a vein in the ear of the rabbit. Each sample was placed into a lithium heparin tube. The tubes containing blood were left at room temperature for two hours to allow CsA to equilibrate between red cells and plasma. Plasma was then separated and frozen until the assay was performed. The radioimmunoassay" "was performed with a kit provided by Sandoz Ltd, and the accuracy of the assay was monitored by control samples where the concentration of CsA was known.

\section{ADMINISTRATION OF CSA}

The topical instillation of CsA $1 \%$ comprised 2 drops, $(100 \mu \mathrm{l})$. Topical CsA was administered five
CsA Concentration

( $\mathrm{ng} / \mathrm{ml})$

$\circ(138)$

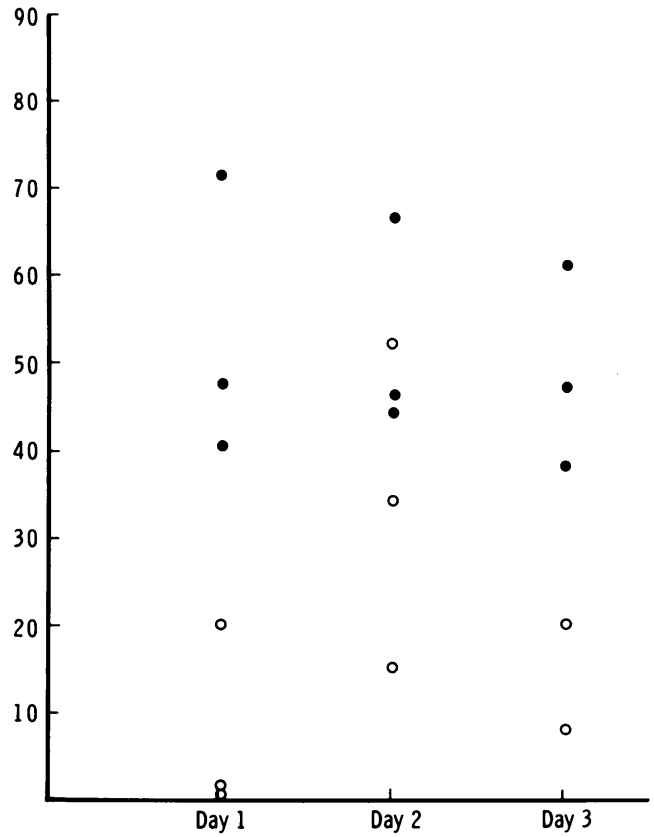

Fig. 2 Plasma and aqueous levels of Cs A following topical CsA five times a day to healthy eyes. Samples were obtained daily; aqueous was obtained from the fellow eye. The solid spots indicate plasma levels and the open circles aqueous levels.

times a day. The intramuscular administration comprised $5 \mathrm{ml} \mathrm{CsA} 1 \%$ containing $50 \mathrm{mg}$ CsA.

Experiment 1. CsA 1\% was administered topically five times a day for three days to healthy rabbit eyes. Samples of plasma and aqueous from the same eye

Table 1 Average plasma and aqueous concentration of Cs $A$ following topical and systemic administration

\begin{tabular}{|c|c|c|c|}
\hline & $\begin{array}{l}\text { No. of } \\
\text { rabbits }\end{array}$ & $\begin{array}{l}\text { Mean plasma } \\
\text { conce'ntration } \\
n g / m l\end{array}$ & $\begin{array}{l}\text { Mean aqueous } \\
\text { concentration } \\
\text { ng/ml }\end{array}$ \\
\hline $\begin{array}{l}\text { Topical CsA to healthy rabbit } \\
\text { cyc. Aqueous sampled } \\
\text { from the same cye }\end{array}$ & 5 & 116 & 27 \\
\hline $\begin{array}{l}\text { Topical CsA to healthy rabbit } \\
\text { cye. Aqueous sampled } \\
\text { from fellow cye }\end{array}$ & 3 & 51 & 18 \\
\hline $\begin{array}{l}\text { Topical CsA to rabhit cyc } \\
\text { with a corncal graft. } \\
\text { Aqueous sampled from the } \\
\text { same cye }\end{array}$ & 6 & 28 & 23.5 \\
\hline $\begin{array}{l}\text { Intramuscular CsA } 50 \mathrm{mg} \text { to } \\
\text { rabbit. Plasma sampled } \\
\text { daily. Aquecous not } \\
\text { sampled }\end{array}$ & 3 & $48 \cdot 3$ & - \\
\hline
\end{tabular}

SI conversion: $\mathrm{ng} / \mathrm{mg}=\mu \mathrm{g} / \mathrm{l}$. 


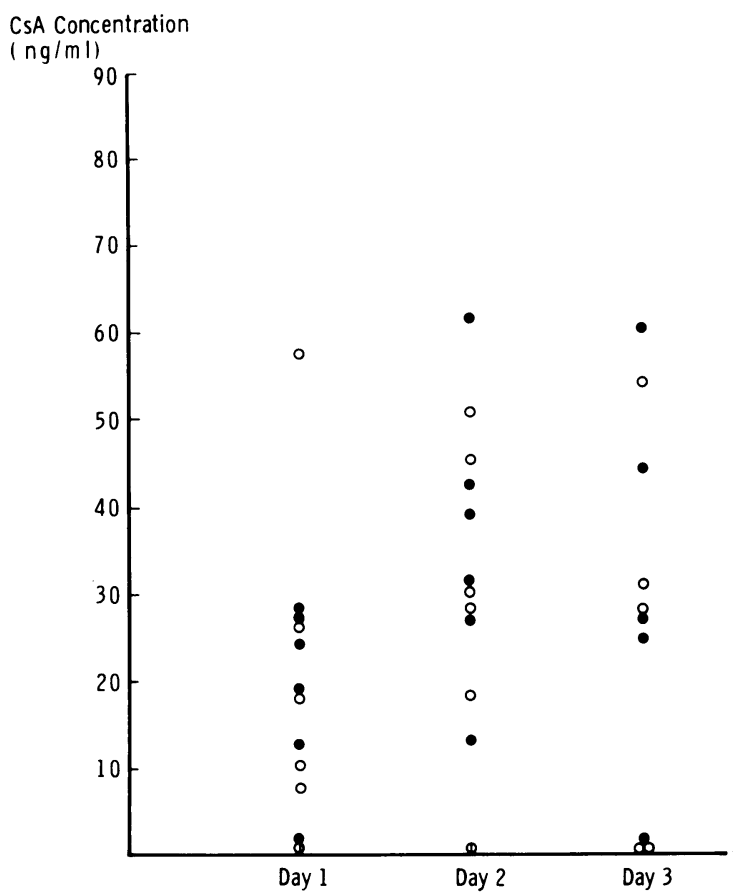

Fig. 3 Plasma and aqueous levels of Cs A obtained following topical Cs A five times a day to eyes bearing a corneal graft. Samples were obtained daily. The solid spots indicate plasma levels and the open circles aqueous levels.

were obtained daily, and the CsA levels determined. $\mathrm{n}=5$.

Experiment 2. CsA $1 \%$ was administered topically five times a day for three days to healthy rabbit eyes. Samples of plasma and aqueous from the fellow unoperated eye were obtained daily and the CsA levels determined. $\mathrm{n}=3$.

Experiment 3. CsA was administered topically five times a day for three days to rabbits which had received a corneal graft 7-10 days previously. Samples of plasma and aqueous from the eye containing the graft were obtained daily and the CsA levels determined. $\mathrm{n}=6$.

Experiment 4. An intramuscular injection of $50 \mathrm{mg}$ CsA was administered to each of three rabbits. Samples of plasma were obtained subsequently daily for three days and the CsA levels determined. $n=3$.

\section{Results}

Figs. 1-3 demonstrate the plasma and aqueous levels of CsA following the topical administration of CsA, and Fig. 4 the plasma level of CsA obtained on three days following single intramuscular injection of 50 $\mathrm{mg}$ CsA. Table 1 demonstrates the average plasma and aqueous levels of CsA obtained.

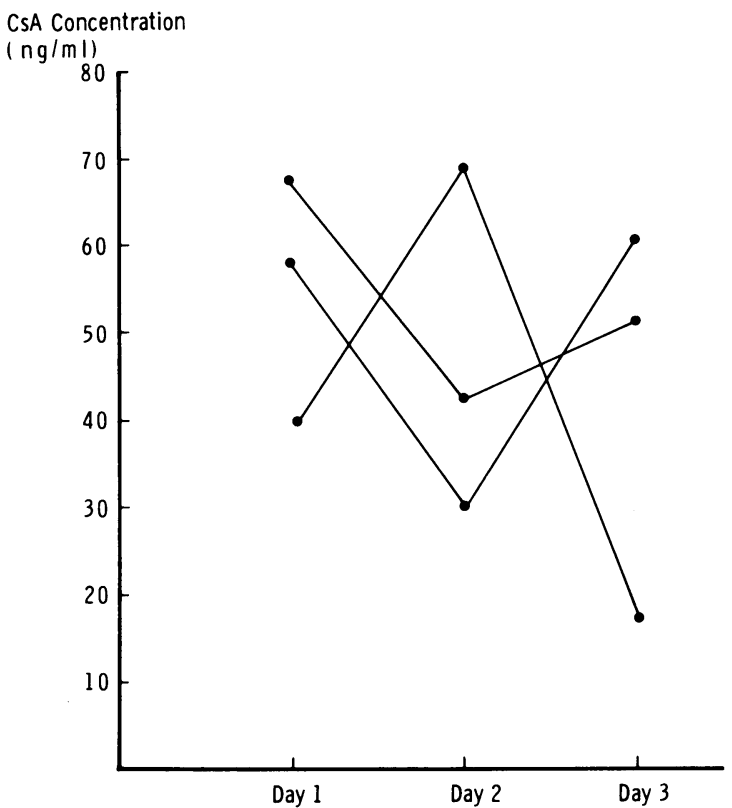

Fig. 4 Plasma levels of CsA obtained on the three days following an intramuscular injection of $50 \mathrm{mg} \mathrm{CsA}$.

The plasma levels of CsA following topical administration to healthy eyes (Figs. 1,2) were significantly higher $(\mathrm{p}<0.01$, Wilcoxon rank test $)$ than the plasma levels following topical administration to eyes which had received corneal grafts (Fig. 3).

There was no significant difference between the plasma levels of CsA measured over the three days following an intramuscular injection of $50 \mathrm{mg}$, CsA (Fig. 4) and the plasma level measured daily on the rabbits which received topical CsA five times a day to healthy eyes (Figs. 1,2) (Wilcoxon rank test).

The plasma levels of CsA within the group which received the intramuscular CsA (Fig. 4) were significantly higher than the plasma levels in the group which received topical CsA five times a day to the eye which had received the corneal graft (Fig. 3) $(0 \cdot 02>$ $\mathrm{p}>0.01$, Student's $t$ test). There was no significant difference between the aqueous levels shown in Figs. 1,2 , and 3 .

\section{Discussion}

The investigation confirms the findings by Foets $e t$ al. $^{+7}$ that systemic levels of CsA are recorded when CsA is administered topically to rabbit eyes. A single intramuscular injection of $25 \mathrm{mg} / \mathrm{kg}$ CsA results in a plasma level which is less than that normally considered therapeutic, namely $>100 \mathrm{mg} / \mathrm{l} .{ }^{11}$ This plasma level tends to persist at least over three days. 
Aqueous levels of CsA following topical administration are lower than plasma levels and appear to be uninfluenced by the presence of a corneal graft or when the CsA is administered to the other eye.

As the plasma level of CsA following topical administration to healthy rabbit eyes is found to be similar to that following an intramuscular injection of CsA, this suggests that sufficient CsA is absorbed to act systemically. As less CsA is absorbed when administered topically in the early postgraft period, then clearly the conditions do not favour absorption, as might be expected, but reduce the absorption.

It is possible that topical administration in the early postgraft period is ineffective, as the absorption is reduced. It should be noted that, when Foets et al. ${ }^{7}$ administered CsA topically to the fellow eye in a rabbit which had received a corneal graft, the fellow eye had also been operated on. It is possible that the failure to prevent rejection may have been due to poor absorption of CsA from the injured fellow eye in the early postgraft period. Topical administration of CsA to an uninjured eye would appear in the animal model to be a potentially useful mode of administering CsA. Clearly further investigation is required to determine whether this is true in the human. In relation to corneal grafting, unless clear evidence of a local action can be demonstrated, it is possible it may be of little use in the early postgraft period. Administration to the unaffected eye or systemic administration would appear to be more suitable methods of giving the drug during this important period.
We gratefully acknowledge assistance from $\mathrm{Mr} \mathrm{A} J$ Bron, Nufficld Laboratory of Ophthalmology, Oxford, Professor P J Morris, Nuffield Department of Surgery, Oxford, and Dr J F Borel of Sandoz Ltd.

\section{References}

1 Shepherd WFI, Coster DJ, Chin Fook T, Rice NSC, Jones BR. Effect of cyclosporin A on the survival of corneal grafts in rabbits. Br J Ophthalmol 1980); 64: 148-53.

2 Bell TAG, Easty DL, McCullagh KG. A placebo controlled blind trial of cyclosporin $A$ in prevention of corneal graft rejection in rabbits. BrJ Ophthalmol 1982; 66: 303-8.

3 Hunter PA, Garner A, Wilhelmus KR, Rice NSC. Corneal graft rejection: a new animal model and cyclosporin $\mathrm{A} . \mathrm{Br} J$ Ophthalmol 1982; 66: 292-302

4 Foets B, Vanderveeren P, Missotten L. Inhibition of the allograft reaction in corneal transplantation by cyclosporin $A:$ an experimental study with rabbits. Bull Soc Belge Ophtalmol 1983; 206: $21-6$.

5 Kana JS, Hoffman F, Buchen R, Krolic A, Wiederhold M. Rabbit corneal allograft survival following topical administration of cyclosporin A. Invest Ophthalmol Vis Sci 1982; 22: 686-90.

6 Salisbury JD, Gebhardt BM. Suppression of corncal allograft reactions by cyclosporin A. Arch Ophthalmol 1981; 99: 164()-3.

7 Foets B, Missotten L, Vanderveeren P, Goossens W. Prolonged survival of allogenic corneal grafts in rabbits treated with topically applied cyclosporin A: systemic absorption and local immunosuppressive effect. Br J Ophthalmol 1985; 69: 6(0)-3.

8 Morris PJ. Cyclosporin A overview. Transplantation 1981; 82: 349-53.

9 Morris PJ. Some experimental and clinical studies of cyclosporin A in renal transplantation. Transplant Proc 1982; 14: 525-7.

10 Donatsch P, Abisch E, Homberger M, Traber R, Trapp M, Voges $R$. A radioimmunoassay to measure cyclosporin $A$ in plasma and serum samples. J Immunoassay 1981; 2: 19-32.

11 Keown PA, Stiller CR, Ulan RA, Wall WJ, Sinclair NR, Carruthers G. Immunological and pharmacological monitoring in the clinical use of cyclosporin A. Lancet 1981 ; i: 686-9.

Accepted for publication 20 February 1986. 